\title{
DIGITAL STORAGE AND THE DATA COLLECTION FOR THE SEISMIC PREVENTION: A COMPARISON FROM THE ITALIAN RECENT EXPERIENCES
}

\author{
E. Brusa ${ }^{a}$ \\ ${ }^{a}$ Dept. of Architecture and Urban Planning (DAStU), Politecnico di Milano, Milan, Italy - enrica.brusa@polimi.it
}

KEY WORDS: Seismic prevention, Built Heritage, Emergency management, Data storage

\begin{abstract}
:
Concerning the care of our Built Heritage, one of the most important problem that was observed after an earthquake is the speed in the reaction, aiming to minimize the damages provoked by the shakes. As a matter of fact, the necessary time for the reaction of the rescue teams should be not too long, in order to avoid further damages provoked by the future shakes. Thus, the best way to minimize this type of damage is to design appropriate shoring systems that replace the lack of stiffness provoked by earthquake as soon as possible. In this sense, it's necessary to know many information of a damaged monument, such as: the geometry, the materials and the structural characteristics, the presence of previous alterations and/or restorations, etc. Unfortunately, the accessibility to this kind of information is not always available after an earthquake, due to the possible damages provoked to the buildings, where the public archives and the documentation are normally stored (L'Aquila 2009, Amatrice 2016).

The awareness of this problem started immediately after the serious earthquake that hit the city of L'Aquila in 2009. Then, it became more urgent after 2016, when the extended and continued earthquake in the Centre of Italy provoked increasing damages to buildings and monuments. In particular, an important role in the churches' collapses that had occurred during this last earthquake was due to the difficulty in finding the necessary information to design proper shoring systems.

Nowadays, starting from the experience of L'Aquila, teams composed by functionaries of the Ministry of Culture, engineers from different universities and special members of the Fire Brigade have developed and improved various models for the management of the emergency phases. Using the modern geomatics tools (i.e. Unmanned Aerial Systems (UAS), Terrestrial Laser Scanners (TLS), Remotely Piloted Aircraft Systems (RPAS)), it's possible to achieve the digital acquisition of many building's data and characteristics (i.e. through the 3D Object recognition and reconstruction, the point cloud analysis, etc.).

This article examines some of the most interesting solutions that were adopted after the recent Italian earthquakes (L'Aquila 2009, Emilia-Lombardia 2012, Centre of Italy 2016) by some of the major public Entities (Superintendences, Italian Fire Brigade). Moreover, it evaluates the possibility to enhance both the competences and the tools that have been until now developed, with the purpose to use them for an effective Built Heritage prevention, without having to wait a new emergency phase to adopt them.
\end{abstract}

\section{INTRODUCTION}

During last years, there has been an increasing application of geomatics in the field of architecture. Above all, this was due to both the introduction of increasingly sophisticated algorithms and the consequent development of the softwares for the images processing. As things stand, the complexity of the workflow operations has been considerably reduced, ensuring a greater diffusion of geomatic detection systems. Thus, the same improvement has occurred in the field of cultural heritage, with an increasing number of applications and studies related to the new digital tools for the geometric surveys.

In particular, the development of these studies has been applied to different scales, from the urban one, with the survey of building complexes or entire blocks, to the one of individual objects, such as statues or paintings (Ballarin 2017)

The geometric detection by photogrammetric techniques presents several advantages for the cultural heritage: first of all it allows to obtain accurate results; furthermore, these are noninvasive techniques, which allow a good image acquisition level, even for those portions that are not always easily detectable - such as roofs, towers and bell towers elements. Moreover, digital geometric surveys could be used for an everincreasing number of purposes: from the one of valorisation and dissemination - i.e. through the application of virtual reconstructions (Bevilacqua et al. 2019, Dhanda et al. 2019.) -
, to the one of heritage protection during emergencies - i.e. through the detection of the structural building conditions.

This article will address some application cases for the detection of earthquake damages. The general aim of the work is to highlight positive aspects and advantages carried out by geomatics in the field of the Built Heritage protection. The proposed case studies concern the last three major Italian earthquakes, which occurred in 2009, 2012 and 2016. At the end some considerations regarding the results achieved and some comments on future developments will be presented.

\section{GEOMATICS FOR THE CULTURAL HERITAGE}

Concerning the field of Cultural Heritage, geomatic tools can be used not only to acquire geometric information, but also to achieve conservative or enhancement purposes. Digital survey techniques are also particularly useful during emergencies.

Regarding geometric surveys, the photogrammetric techniques are widely used as they allow to obtain a very high level of accuracy. Errors from manual measurements are significantly reduced and the returned tolerance can vary from tens to a single millimetre. However, the quality of the acquired data varies according to the purposes of the survey: thus, a 3D model created to detect the cracks of a damaged building may present a greater tolerance; otherwhise, if the main purpose is to acquire an accurate survey of decorations, 
the tolerance will be smaller. The drawing scale may therefore be different depending on the objective of the survey.

However, even if it is not always necessary, an medium quality level of the 3D model is at least desirable, mostly because the processed point-clouds can be then exploited for several other uses - not only $2 \mathrm{D}$ plans and projections, but also structural models and thematic surveys, such as cracking or degradation maps. Moreover, a processed 3D model could be useful also to create a BIM information system of the detected building, which could be especially useful for the management of future maintenance or restoration works.

In several other cases the 3D model has provided the basis for the reconstruction of some missing parts or elements, especially in the case of sculptural elements, destroyed by degradation or by vandalism (Weigert et al. 2019). Again, the use of three-dimensional models as a tool for the enhancement of Cultural Heritage, represents a practice that is today increasingly common, as it's shown by virtual reconstructions of portions or entire buildings that no longer exist (Bitelli et al. 2017). In particular, the use of these stratagems represents a strongly multidisciplinary application, which has to combine both the scientific skills and the historical and architectural ones - all necessary for the correct interpretation of buildings that still exhist only in old photographs and drawings.

On the other hand, significant results have come from the application of digital survey techniques in the context of emergencies, in situations where the promptness of response is of primary importance. In such situations, a central role is played by technologies able to offer, in a very short time, precise images of the damaged buildings.

As it is well known, there can be different types of emergency. This article will consider the application of geomatic techniques during the emergency scenarios that are provoked by earthquakes.

\section{CASE STUDIES FROM EARTHQUAKES: A SUMMARY}

As mentioned, when an earthquake occurr, one of the main goals for the protection of Cultural Heritage is the prompt capability to stop the activated kinematic mechanisms. In fact, since neither the place nor the moment of an earthquake can be predicted, it is possible to try to limit its damages, intervening where the buildings show instable behaviours.

In order to be able to carry out the appropriate safety contermeasures, it is necessary to know what the characteristics of the building are: from the geometry to the materials typologies, to the presence of historical-artistic heritage within them. In most of the cases, these data that are not immediately available, due to their general lack or to the impossibility to access the archives, as they're also damaged by the earthquake.

During this kind of situations, neither the surrounding conditions can guarantee the safety of the operators. As a matter of fact, after an earthquake the Built Heritage often present precarious conditions: some portions can threaten to collapse, or the buildings themselves can be situated in particularly vulnerable urban contexts, where also adjacent buildings can constitute a source of danger. The high probability of further aftershocks could then worsen the overall scenario.
An accurate knowledge of the new building configurations is necessary to guarantee the correct planning of the safety countermeasures. These should guarantee both the absence of new collapses and the possibility of being used even during the subsequent restoration works.

Geomatics tools are therefore extremely useful during this phase, as they allow to reach those areas that are no more accessible to the operators. Moreover, they permit to acquire almost immediately the necessary images for the data processing.

In order to detect Built Heritage damages provoked by earthquake both terrestrial and aerial photogrammetric systems can be used. Numerous examples of these applications can be found in recent literature. (Angelini et al. 2017, Dominici et al. 2017a, Fregonese et al. 2017). Some of them will be reproduced below.

The selected examples refer to each of the most recent earthquakes that have struck the Italian territory. All the cases that are here presented cannot obviously be considered significative from a quantitative point of view; however, they represent - in a synthetic way - a good sample of the possible digital survey applications.

\subsection{L'Aquila (2009)}

The earthquake that has occurred in the city of L'Aquila, during the night of 06 April 2009, had a magnitude level of 6.3. The damage caused to the buildings was huges and made unusable over the $50 \%$ of them. In this specific case, a further disadvantage depended from the urban layout of the historic centre: the dense road network presented narrow streets, not guaranteeing the presence of safe escape routes and involving a high risk of collapse of adjacent buildings.

The examined case studies concern examples relating to different survey scales: from the urban typologies of blocks and squares (Dominici et al. 2017b), to the architectural one of single building (Oreni et al. 2017). The choosen methodology, while adopting different tools, was the same: data were collected by using terrestrial laser scanner (TLS) and georeferencing all the acquired CGPs. The terrestrial data acquisition was integrated with further data collected by UAV systems.

In most of the analysed examples, different tool configurations were tested for each building-i.e. varying the camera parameters and/or the number of the acquired images. The comparison of the obtained results, according to different setting parameters, showed that they were quite comparable, both in terms of quality and precision. So, also this circumstance allows us to confirm the usefulness of digital photogrammetry in such emergency scenarios.

Concerning the case studies examined for the Aquilan context, it was interesting to note two different aspects of the application of geomatic techniques, that are respectively related to one possible development and to one possible critical issue.

For the first aspect, a good example is the case study of the Basilica di Collemaggio (Oreni et al. 2017), whose 3D model, has been elaborated starting from the damage detection after the earthquake. This model was then used as the base for the set-up of an 'Historical BIM' model. The design of such BIM model has associated each singular built element, 
appropriately listed, with its own characteristic information such as the material and / or its previous interventions.

Thus, the development of such a management tool - which was the result of a considerable organizational effort - helped to demonstrate its usefulness also in the restoration field. In fact, it allows to maintain always a good control on the building interventions, being able to implement the model data with the ones relating to future interventions.

Instead of, for the second aspect, one of the major critical point to be faced to during emergency concern the plan of the survey itself. In such situation, the design of a flexible and accurate workflow that could be suitable to different contexts become really important. Several precarious conditions may occur during a seismic emergency, as it has been shown - for instance - during the survey of the village of Fontecchio(AQ). In this case, the researchers could not use the automatic georeference mode, as there was no internet signal in the village. For this reason, the entire survey was carried out in the manual configuration, emphasizing once again how both the setting up of the workflow and the presence of qualified operators are able to make a difference.

\subsection{Lombardia earthquake (2012)}

The Mantua earthquakes, which occurred at the end of May 2012, involved an area situated between the regions of Emilia Romagna, Lombardia and Veneto. The first earthquake, which occurred on May the $20^{\text {th }}$, had a Richter magnitude of 5.9. The second major shock, which instead occurred on May the $29^{\text {th }}$, was comparable to the first, as it was characterized by a magnitude of 5.8 .

The presence of two different shocks, both characterized by a high magnitude and by a close time interval, provoked many damages to the buildings. In recent times, this was the first example that showed us the importance of promptly intervening to secure our Built Heritage.

Above all, the examined literature concerns the studies carried out for the province of Mantua. In particular, some surveys carried out by Politecnico di Milano has been retrieved (Adami et al. 2016). These surveys, which were required by the Diocese of Mantua, were performed by a group of researchers that had to detect the damage in some churches. The final results are particularly interesting for several reasons:

- $\quad$ first of all, they have allowed us to show once again the advantages offered by adopting UAV technology to detect building damage: speed of data acquisition, operators' safety, efficiency, cost-effectiveness of operations, etc ;

- moreover, all the interventions have been carefully designed, taking into consideration both the constraints and the characteristics which were present in the different scenarios, choosing the most appropriate tools from time to time. The survey operations were limited to those strictly necessary for the set-up objectives.

Both the camera calibration parameters and the resolution level of the images have been carefully set-up, according to both the different design purposes and the churches complexities - i.e. their conformation/damage situation. The final outcomes of these surveys have shown that such good results can also be obtained by setting up the parameters on a medium resolution level - such as a not so high image quality or the use of a minimum number of CGPs markers.

Moreover, in some cases the point clouds that were processed from the photogrammetric surveys have been then used for the elaboration of some structural models. Also in this case the performed results proved to be reliable.

\subsection{Centre of Italy (2016)}

The earthquake that struck central Italy in 2016 was an even more significant example of what the damage provoked by the repetition of the shakes could be. In fact, many collapses that have occurred among the Built Heritage were caused by the aftershocks.

As it is well known, the first episode of the 'seismic swarm' took place on August, the $24^{\text {th }}$, having a magnitude of 6.1 . Subsequently, other shocks of comparable magnitude occurred two months later: a new earthquake with a 5.9 magnitude happened on October, the $29^{\text {th }}$; while an other with a 6.5 magnitude occurred on October, the $30^{\text {th }}$. Finally, a last sequence of shakes higher than the $5^{\text {th }}$ grade happened on January, the $18^{\text {th }}$.

The area that was interested by the earthquake belongs to four different regions - Umbria, Marche, Abruzzo and Lazio - and was hit with different intensities during the different shocks.

A large part of the collapses was caused precisely by the repetition of high magnitude shakes at a close time-interval. After the first earthquake, both the vastness of the area and the high number of damaged buildings, combined with the impossibility of forecasting the subsequent shocks, has ensured that a large number of the Built Heritage had not yet been secured when the subsequent shocks occurred, permitting further damage to the general assets.

The use of geomatic techniques has been widely used also in this emergency phase: the special units of the Fire Brigade have used UAV to carry out the preliminary damage assessment, as well as the technicians in charge of carrying out first geometric surveys used terrestrial and aerial detection systems.

An emblematic case study was given by the monitoring of the damage in S. Agostino church, where photogrammetric surveys were carried out almost immediately after the various shocks. This case study, which has already been discussed during the previous conference (1), represents a particularly interesting example, because of some emerged features and problems. Firstly, it is worth noting the discreet promptness with which the surveys were carried out - the surveys were carried out, respectively: 12 days after the first shock of August, the $24^{\text {th }}$; one month after the second one of October, the $29^{\text {th }}$; the day after the fourth one of January, the $18^{\text {th }}$. This was mainly due to the collaboration started with the Fire Brigade teams, which provided the researchers with the support of both their own technicians and means

The results obtained from the comparison between the three different 3D models were also important. These models were elaborated starting from the images that were acquired during the different survey phases.

The comparison among the models showed once more the importance of knowing how to precisely define the survey workflow. This foresight is therefore even more important, especially in emergencies, where both the conditions and the time for the survey are quite precarious. 
In addition, the comparison between the processed 3D models, which were related to the different damage conformations of the church, has constituted a useful methodology for verifying the progress of the damage mechanisms. The obtained photogrammetric outcomes and the 3D models were used to find accurate information on the structural behaviour of the building. These studies may subsequently be helpful for other studies on the masonry behaviour during an earthquake.

Later on, the 3D models will also be used to elaborate a virtual reconstruction of how S. Agostino church was before the earthquake.

Since a 3D model had not been realized before the earthquake, the reconstruction of the 'ex-ante' condition can be realized only through a deep comparison between the existing photographs and between those and the 'ex-post' 3D model.

Obviously, the surveys on the S. Agostino church do not correspond to the only reference of what has been done, and many other examples can be found in literature (Gagliolo et al 2017). However, this case study well represents which results could be obtained by adopting such photogrammetric toolsboth the terrestrial and the aerial ones -, as well as which their critical points and their future developments could be.

\section{DISCUSSION}

In the previous paragraphs, some significant case studies and recent literature researches have been re-proposed. The selected case studies were focused on results that have been developed by applying geomatics technologies during earthquake emergencies, aiming to survey the level of damage for the Built Heritage. Through these examples, it was possible also to highlight which the main features offered by these technologies and working methods are, including also their main advantages and disadvantages.

Generally, facing to an emergency scenario, it has been seen how the advantages offered by geomatic are several: for instance, the adopted photogrammetric tools permitted to acquire good results, with accurate and detailed images even when the boundary conditions were not optimal.

Almost paradoxical in this sense was the case of the $S$. Agostino church: in this case, it was possible to detect what was happening almost simultaneously to the shocks, but it was not possible to intervene just as promptly. The use of photogrammetric techniques has allowed us to know in detail what was happening, but the acquired knowledge wasn't enough to save the church from collapses.

However, the use of such geomatic tools has demonstrated the capability to reach even the high-risk areas, always allowing to preserve the operators' safety -i.e. using the remote control of the UAV systems.

Furthermore, permitting a detailed knowledge of which the situation of the Built Heritage is, both the data collection and the subsequent 3D models processing have represented, in most of the cases, a valid tool from which it has been possible to set up the design of the buildings' safety countermeasures. Other positive aspects can then be found in the increasing speed of both the data acquisition phase and the image processing that is performed by softwares.

All these aspects undoubtedly represent an important parameter that has to be considered in the cost-effectiveness design for the restoration of the damaged Cultural Heritage.
On the contrary, few critical elements remain. They are mainly linked to some elements of the emergency context or to operative conditions - for instance: an obstacle for the survey could be constituted by the presence of the safety contermeasures or by the debris, as well as by other parameters such as the external light conditions. For this reason, the definition of an accurate workflow become particularly significative to guarantee the success of survey.

\section{CONCLUSIONS}

It is therefore not a matter of inventing new techniques, but of applying the ones that already exist. These should always be adapted to the inquired buildings features, each time being able to perform a well-tailored workflow.

Thus, the problem appears to be of both a qualitative nature linked to the need of establishing criteria and working methods specific for each case - and a quantitative one. In fact, it is still necessary to underline how, although many digital surveys of our Heritage have already been done - especially during recent years -, much still remains to be done for the collection of Built Heritage digital data.

An accurate survey of the historic buildings could represent a valuable resource for the sharing of the building knowledge. Thus, more efforts have still to be performed to increase the number of the digital surveyed Built Heritage during 'peacetime'.

The presence of these surveys, together with the creation of point clouds of geometric data, would be very useful for carrying out a first comparison between the 'ex ante' and the 'ex-post' conditions of buildings. Moreover, it would also allow to reconstruct with a greater precision the kinematic mechanisms that are activated by earthquakes, and it would be a useful reference during the reconstruction/restoration phase of the damaged Heritage - i.e. through the development and the updating of a BIM model.

The presence of an accurate relief could also be very useful even in the case of damage to the decorative elements, for which it would be easier to carry out the cataloguing of the rubble and the consequent re-composition of the decorations, comparing their fragments with the detailed relief that was previously done (Acconci and Porro 2018) (2).

A greater caution should instead always be present in the field of complete reconstructions - both in the real and in the virtual one. Thus, where the reconstruction of a fresco is largely accepted and even pursued, the same could not always be said for the reconstruction of whole buildings: the 'com'era $e$ dov'era' criterion hides within it, behind the apparent naivety of intent, multiple deceptions. An a-critical reconstruction aimed at restoring a building in its 'original' condition maybe just thanks to the help of a virtual model - would anyhow represents an anti-historical intervention.

On the other hand, instead, the use of scientifically detected $3 \mathrm{D}$ models could represent a good tool for maintaining that sense of identity that links communities to their Heritage, hugely damaged by the earthquake.

Having highlighted this, the exploitation of the virtual reality appears to be better used only in the field of education and in the one of cultural dissemination. In fact, it would represent a valid instrument for the knowledge recovery in case of the Architectural Heritage loss. 
On the one hand, it would allow us to better understand how the building was in the past and how it had been built; on the other, it would also contribute to the transformation of the building itself from being a concrete witness to becoming a collective evocation of the identitarian memory of the community.

\section{NOTES}

(1) GEOMATICS \& RESTORATION - Conservation of Cultural Heritage in the Digital Era, 22-24 May 2017, Florence, Italy

(2) https://www.ilgiornaledellarte.com/articoli/articoli/2018/ 4/129271.html (accessed: March 2019)

\section{REFERENCES}

Acconci, A. and Porro, D.. (Eds.), 2018. Rinascite - Attività di recupero e conservazione per il patrimonio reatino. Electa, 2833

Adami, A., Chiarini, S., Cremonesi, S., Fregonese, L., Taffurelli, L. and Valente, M.V., 2016. The survey of cultural heritage after an earthquake: the case of Emilia-Lombardia in 2012. Int. Arch. Photogramm. Remote Sens. Spatial Inf. Sci., XLI-B5, 161-168. doi:10.5194/isprsarchives-XLI-B5-1612016

Agostiano, M. and Concas, D., 2017. Prevenire l'emergenza: le verifiche di vulnerabilità sismica come strumento di conoscenza e salvaguardia del patrimonio culturale. Lo Stato dell'Arte 14, Proceedings of the XIV National Conference IGIIC, L'Aquila, 71-78

Angelini, M. G., Baiocchi, V., Costantino, D., and Garzia, F., 2017. Scan to BIM for $3 d$ reconstruction of the Papal Basilica of Saint Francis in Assisi in Italy. Int. Arch. Photogramm. Remote Sens. Spatial Inf. Sci., XLII-5/W1, 47-54. doi.org/10.5194/isprs-archives-XLII-5-W1-47-2017

Arbace, L., Sonnino, E., Callieri, M., Dellepiane, M., Fabbri, M., Idelson, A.I., Scopigno, R., 2013. innovative uses of 3D digital technologies to assist the restoration of a fragmented terracotta statue. Journal of Cultural Heritage, Vol. 14 (4)

Ballarin, M., Balletti, C., Faccio, P., Guerra, F., Saetta, A., and Vernier, P., 2017. Survey methods for seismic vulnerability assessment of historical masonry buildings. Int. Arch. Photogramm. Remote Sens. Spatial Inf. Sci., XLII-5/W1, 5559. doi.org/10.5194/isprs-archives-XLII-5-W1-55-2017

Bevilacqua, M. G., Caroti, G., Piemonte, A., and Ulivieri, D., 2019. Reconstruction of lost architectural volumes by integration of photogrammetry from archive imagery with 3-d models of the status quo. Int. Arch. Photogramm. Remote Sens. Spatial Inf. Sci., XLII-2/W9, 119-125. doi.org/10.5194/isprs-archives-XLII-2-W9-119-2019

Bitelli, G., Dellapasqua, M., Girelli, V. A., Sbaraglia, S., and Tinia, M. A., 2017. Historical photogrammetry and terrestrial laser scanning for the $3 \mathrm{D}$ virtual reconstruction of destroyed structures: a case study in Italy. Int. Arch. Photogramm. Remote Sens. Spatial Inf. Sci., XLII-5/W1, 113-119. doi.org/10.5194/isprs-archives-XLII-5-W1-113-2017
Chiabrando, F., Di Lolli, A., Patrucco, G., Spanò, A., Sammartano, G., and Teppati Losè, L., 2017. Multitemporal 3D modelling for cultural heritage emergency during seismic events: damage assesment of S. Agostino church in Amatrice (RI). Int. Arch. Photogramm. Remote Sens. Spatial Inf. Sci., XLII-5/W1， 69-76. doi.org/10.5194/isprs-archives-XLII-5W1-69-2017

Dhanda, A., Reina Ortiz, M., Weigert, A., Paladini, A., Min, A., Gyi, M., Su, S., Fai, S., and Santana Quintero, M., 2019. Recreating cultural heritage environments for VR using photogrammetry. Int. Arch. Photogramm. Remote Sens. Spatial Inf. Sci., XLII-2/W9, 305-310. doi.org/10.5194/isprsarchives-XLII-2-W9-305-2019

Dominici, D., Alicandro, M., Rosciano, E., and Massimi, V., 2017a. Multiscale documentation and monitoring of L'Aquila historical centre using UAV photogrammetry. Int. Arch. Photogramm. Remote Sens. Spatial Inf. Sci., XLII-5/W1, 365371. doi.org/10.5194/isprs-archives-XLII-5-W1-365-2017.

Dominici D., Alicandro M. and Massimi, V., 2017b. UAV photogrammetry in the post-earthquake scenario: case studies in L'Aquila. Geomatics, Natural Hazards and Risk, 8:1, 87103. doi:10.1080/19475705.2016.1176605

Fregonese, L., Campera, A., Scala, B., and Adami, A., 2017. The 2012 earthquake: an abacus of surveys and interventions in Mantua churches. Int. Arch. Photogramm. Remote Sens. Spatial Inf. Sci., XLII-5/W1, 31-38. doi.org/10.5194/isprsarchives-XLII-5-W1-31-2017

Gagliolo, S., Fagandini, R., Federici, B., Ferrando, I., Passoni, D., Pagliari, D., Pinto, L., and Sguerso, D., 2017. Use of UAS for the conservation of historical buildings in case of emergencies. Int. Arch. Photogramm. Remote Sens. Spatial Inf. Sci., XLII-5/W1, 81-88. doi.org/10.5194/isprs-archivesXLII-5-W1-81-2017

Mileto, C. and Vegas, F., 2017. Survey and restoration. Int. Arch. Photogramm. Remote Sens. Spatial Inf. Sci., XLII-5/W1, 3-7. doi.org/10.5194/isprs-archives-XLII-5-W1-3-2017.

Oreni, D., Brumana, R., Della Torre, S., and Banfi, F., 2017. Survey, HBIM and conservation plan of a monumental building damaged by earthquake. Int. Arch. Photogramm. Remote Sens. Spatial Inf. Sci., XLII-5/W1, 337-342. doi.org/10.5194/isprs-archives-XLII-5-W1-337-2017

Pulcrano, M., Scandurra, S., Minin, G., and di Luggo, A., 2019. 3D cameras acquisitions for the documentation of cultural heritage. Int. Arch. Photogramm. Remote Sens. Spatial Inf. Sci., XLII-2/W9, 639-646. doi.org/10.5194/isprsarchives-XLII-2-W9-639-2019

Valenti, R. and Paternò, E., 2019. A comparison between TLS and UAV technologies for historical investigation. Int. Arch. Photogramm. Remote Sens. Spatial Inf. Sci., XLII-2/W9, 739745. doi.org/10.5194/isprs-archives-XLII-2-W9-739-2019

Weigert, A., Dhanda, A., Cano, J., Bayod, C., Fai, S., and Santana Quintero, M., 2019. A review of recording technologies for digital fabrication in heritage conservation. Int. Arch. Photogramm. Remote Sens. Spatial Inf. Sci., XLII2/W9, 773-778. doi.org/10.5194/isprs-archives-XLII-2-W9$773-201$ 